\title{
Insights on diagnosis and therapeutic decision-making patterns for multiple sclerosis treatment: cross-sectional opinion survey results from Japanese neurologists
}

\author{
Katsutoshi Hiramatsu ${ }^{1 *}$, Masakazu Hase ${ }^{1}$ and Hirofumi Ochi ${ }^{2}$
}

\begin{abstract}
Background: There are few reports about the actual state of diagnosis for multiple sclerosis (MS) in Japan. In addition, in late years multiple disease-modifying drugs (DMDs) were released in Japan, but there are few reports of the actual treatment situation including the choice of DMD as well. Therefore, we conducted a questionnaire survey involving neurologists across Japan to investigate the current practices of diagnosing and determining the treatment strategy for MS.

Methods: A case-based survey was conducted among Japanese neurologists currently treating MS patients with DMD to understand the current situation of MS diagnosis and treatment policy determination in Japan.

Respondents were divided into tertiles, group 1 (one to three), group 2 (four to nine) and group 3 ( $\geq$ ten) by the number of MS patients under management. Results were evaluated as the whole and in each group. Consensus opinion was defined a priori as at least $75 \%$ agreement.

Results: Effective responses were obtained from 205 neurologists by web-based survey. 86.3\% of the respondents answered that they are able to diagnose MS in accordance with the 2010 revised McDonald criteria for MS. This proportion increased in accordance with the abundance of experience gained treating MS patients (trend test: $p<0.014)$. All the respondents answered that magnetic resonance imaging (MRI) was to be used for all suspected clinical relapse regardless of the presence or absence of new signs on any neurological examinations, and even when no neurological exams were performed, suggesting that they value MRI testing as a key criterion for diagnosing MS regardless of treatment experience. While no consensus was achieved on DMD selection to treat naïve patients with different disease activities, most of the respondents answered to choose either IFN $\beta$ products or fingolimod. The neurologists with abundant treatment experience (group 3) would change DMD as the disease activity increased, whereas the less experienced groups (group 1 and 2) replied that they would choose the same DMDs regardless of disease activity level.
\end{abstract}

Conclusions: The present study shed light on diagnosis and treatment decision-making patterns for MS in Japan.

Keywords: Diagnosis, Disease-modifying drug, Multiple sclerosis, Relapsing-remitting multiple sclerosis, Therapeutic measures

\footnotetext{
* Correspondence: katsutoshi.hiramatsu@biogen.com

${ }^{1}$ Biogen Japan Ltd., Nihonbashi 1-chome Mistui Building 14F, 4-1, Nihonbashi

1-chome, Chuo-ku, Tokyo 103-0027, Japan

Full list of author information is available at the end of the article
}

(c) The Author(s). 2018 Open Access This article is distributed under the terms of the Creative Commons Attribution 4.0 International License (http://creativecommons.org/licenses/by/4.0/), which permits unrestricted use, distribution, and reproduction in any medium, provided you give appropriate credit to the original author(s) and the source, provide a link to the Creative Commons license, and indicate if changes were made. The Creative Commons Public Domain Dedication waiver (http://creativecommons.org/publicdomain/zero/1.0/) applies to the data made available in this article, unless otherwise stated. 


\section{Background}

Multiple sclerosis (MS) is an inflammatory demyelinating disease that affects the white matter of the central nervous system. MS is known to be classified into Relapsing-Remitting MS (RRMS) and Primary Progressive MS (PRMS). RRMS is defined as a type of MS in which patients experience relapse and remission over time whereas PRMS is defined as a type of MS in which patients experience gradual and chronic progression of their symptoms from the onset of the disease, which often results in severe disability in patients [1]. In Japan, compared to Western countries, the prevalence of MS is significantly lower, and the current estimated prevalence is $10 / 100,000[2,3]$. The advent of disease-modifying drugs (DMDs) has made it possible to prevent relapse and suppress the progression of physical disabilities [4]. The DMDs that have been approved in Japan include subcutaneous interferon beta-1b (IFN $\beta-1 b$; approved in 2000), intramuscular interferon beta-1a (IFN $\beta-1 a ; 2006)$, fingolimod (FTY; 2011), natalizumab (NTZ; 2014), glatiramer acetate (GA; 2015), and dimethyl fumarate (DMF; 2016). For diagnosis of MS, the globally accepted diagnostic criteria proposed by McDonald has been widely used [5]. This criteria set, featured by the use of MRI findings for demonstrating the temporal and spacial multiplicity of inflammatory demyelinating lesions in the central nervous system, was first reported in 2001 and subsequently revised, mainly in MRI criteria, in 2005 and 2010 [5-9]. In Japan, an original criteria set is available for diagnosing MS as a designated intractable disease, which includes MRI criteria developed based on the 2010 revised McDonald criteria [10]. Healthcare system of Japan exempts a major financial burden of patients treated with DMDs if they satisfy both diagnostic criteria for MS as a designated intractable disease and other certain conditions. This requires precise understanding of MS diagnostic criteria and diagnosing of MS in accordance with these in physicians treating MS, suggesting a wide acknowledgement of the McDonald criteria. In terms of the selection of DMDs, since few head-to-head clinical trials assessing a prognosis as an endpoint have been conducted, the Treatment Guidelines for Multiple Sclerosis 2010 [9], as well as treatment response, safety, disease severity, and history of DMD use are used as the basis for drug selection.

In this study, we conducted a questionnaire survey involving neurologists across Japan to investigate the current practices of diagnosing and determining the treatment strategy for MS in Japan.

\section{Methods}

This was a cross-sectional survey, conducted through the Internet from April 11 to 18, 2016 by M3 Inc. (Tokyo, Japan). M3 Inc. (Tokyo, Japan) conducted the survey using their healthcare professional panel. A total of 3743 registered neurologists were screened in a preliminary survey and $376(10.0 \%)$ of them fully responded, and 269 (7.2\%) neurologists who were treating MS patients with DMDs at the time of survey were included in the questionnaire survey. The questionnaire used was basically the Japanese-translated version of the one used in previous studies conducted in the U.S. $[11,12]$, and it consisted mostly of the same questions as the English version. After responses were collected, de-identified data were provided by M3, Inc. for the analysis, so that no individual responses were known to us or anyone else involved in data analysis or manuscript development.

Consent to the use and publication of survey results was obtained from all respondents along with the completed questionnaires.

\section{Data analysis}

Respondents with valid responses to the questionnaire were included in the analysis. The survey results were summarized descriptively, and a response concordance rate of $\geq 75 \%$ was considered to indicate consensus [11, 12]. Respondents were stratified by tertiles of the number of MS patients under care at the time of survey as a measure of recent experience with MS treatment. This measurement was employed because the treatment paradigm of MS in a clinical setting could have been shifted during 2 years before the survey due to the launch of 2 DMDs in Japan; therefore, the current number of MS patients under care could capture an up-to-date MS treatment experience of the respondents. Respondents were classified into groups 1 (1-3 patients); $n=69,2$ (4-9); $n=58$ and $3(\geq 10) ; n=78$, and treatment experience with MS was assessed in relation to survey results. Intergroup comparison was performed using the one-way analysis of variance (ANOVA) for continuous variables and the chi-square test for categorical variables. For the intergroup comparison of trend with increasing treatment experience, the Cochran-Armitage test was used for binary variables and the Cochrane-Mantel-Haenszel test for other variables [13]. All tests were exploratory and not adjusted for differences in demographic factors between groups or multiplicity of analysis. All tests were performed at a two-sided significance level of $5 \%$ using SAS Release 9.3 (SAS Institute).

\section{Results}

\section{Demographics of respondents}

Valid responses were obtained from 205 of the 269 neurologists to whom the questionnaire was sent, yielding a response rate of $76.2 \%$. The demographics of the 205 respondents are summarized in Table 1 . The mean number of MS patients under care was 8.78 , with $70.3 \%$ of the respondents having more than 10 years of 
Table 1 Respondent characteristics

\begin{tabular}{|c|c|c|c|c|c|}
\hline \multirow[t]{2}{*}{ Characteristics } & \multirow{2}{*}{$\begin{array}{l}\text { Overall } \\
(n=205)\end{array}$} & \multicolumn{3}{|c|}{ Sub-group by number of MS patients under care } & \multirow[t]{2}{*}{$P$ value } \\
\hline & & $\begin{array}{l}\text { Group 1: } \\
1-3 \text { patients }(n=69)\end{array}$ & $\begin{array}{l}\text { Group 2: } \\
\text { 4-9 patients }(n=58)\end{array}$ & $\begin{array}{l}\text { Group 3: } \\
\geq 10 \text { patients }(n=78)\end{array}$ & \\
\hline \multicolumn{6}{|l|}{ Age, n (\%) } \\
\hline $20 \mathrm{~s}$ & $4(2.0)$ & $3(4.3)$ & $0(0.0)$ & $1(1.3)$ & \multirow[t]{5}{*}{0.197} \\
\hline $30 \mathrm{~s}$ & $65(31.7)$ & $25(36.2)$ & $17(29.3)$ & $23(29.5)$ & \\
\hline $40 \mathrm{~s}$ & $80(39.0)$ & $25(36.2)$ & $24(41.4)$ & $31(39.7)$ & \\
\hline $50 \mathrm{~s}$ & $45(22.0)$ & $13(18.8)$ & $13(22.4)$ & $19(24.4)$ & \\
\hline$\geq 60 \mathrm{~s}$ & $11(5.4)$ & $3(4.3)$ & $4(6.9)$ & $4(5.1)$ & \\
\hline $\begin{array}{l}\text { Number of MS patients under care, } \\
\text { mean } \pm \text { SD, (min-max) }\end{array}$ & $\begin{array}{l}8.78 \pm 8.92 \\
(1-50)\end{array}$ & $2.35 \pm 0.78$ & $5.14 \pm 1.03$ & $17.17 \pm 9.54$ & $<0.001^{*}$ \\
\hline $\begin{array}{l}\text { Approximate percentages of patients } \\
\text { with MS under care, mean } \pm \text { SD, (min-max) }\end{array}$ & $\begin{array}{l}6.56 \pm 7.64 \\
(1-60)\end{array}$ & $\begin{array}{l}3.14 \pm 2.63 \\
(1-10)\end{array}$ & $\begin{array}{l}5.41 \pm 7.41 \\
(1-50)\end{array}$ & $\begin{array}{l}10.44 \pm 9.01 \\
(1-60)\end{array}$ & $<0.001^{*}$ \\
\hline \multicolumn{6}{|c|}{ Years of post-residency treatment experience with MS, n (\%) } \\
\hline$<3$ years & $8(3.9)$ & $4(5.8)$ & $2(3.4)$ & $2(2.6)$ & \multirow[t]{6}{*}{0.009} \\
\hline $3-5$ years & $16(7.8)$ & $9(13.0)$ & $2(3.4)$ & $5(6.4)$ & \\
\hline $6-10$ years & $37(18.0)$ & $14(20.3)$ & $12(20.7)$ & $11(14.1)$ & \\
\hline $11-15$ years & $51(24.9)$ & $18(26.1)$ & $14(24.1)$ & $19(24.4)$ & \\
\hline $16-20$ years & $40(19.5)$ & $11(15.9)$ & $14(24.1)$ & $15(19.2)$ & \\
\hline$>20$ years & $53(25.9)$ & $13(18.8)$ & $14(24.1)$ & $26(33.3)$ & \\
\hline \multicolumn{6}{|l|}{ Affiliation, n (\%) } \\
\hline University hospitals & $60(29.3)$ & $19(27.5)$ & $8(13.8)$ & $33(42.3)$ & \multirow[t]{4}{*}{0.019} \\
\hline National/public hospitals & $58(28.3)$ & $18(26.1)$ & $20(34.5)$ & $20(25.6)$ & \\
\hline Hospitals in general & 79 (38.5) & $28(40.6)$ & $27(46.6)$ & $24(30.8)$ & \\
\hline Private practice & $8(3.9)$ & $4(5.8)$ & $3(5.2)$ & $1(1.3)$ & \\
\hline \multicolumn{6}{|l|}{ Membership in professional association ${ }^{\dagger}, \mathrm{n}(\%)$} \\
\hline Japanese Society of Neurology & $204(99.5)$ & 68 (98.6) & $58(100.0)$ & $78(100.0)$ & 0.217 \\
\hline Japanese Society for Neuroimmunology & $36(17.6)$ & $10(14.5)$ & $7(12.1)$ & $19(24.4)$ & 0.108 \\
\hline $\begin{array}{l}\text { Japanese Society of Neurological } \\
\text { Therapeutics }\end{array}$ & $87(42.4)$ & $18(26.1)$ & $27(46.6)$ & $42(53.8)$ & 0.001 \\
\hline \multicolumn{6}{|c|}{ DMDs that had been prescribed in practice ${ }^{\dagger}, \mathrm{n}(\%)$} \\
\hline SC IFNß-1b & $199(97.1)$ & $63(91.3)$ & $58(100.0)$ & $78(100.0)$ & 0.002 \\
\hline IM IFNß-1a & $180(87.8)$ & $60(87.0)$ & $47(81.0)$ & $73(93.6)$ & 0.199 \\
\hline Fingolimod & $171(83.4)$ & $50(72.5)$ & $47(81.0)$ & $74(94.9)$ & $<0.001$ \\
\hline Natalizumab & $32(15.6)$ & $8(11.6)$ & $3(5.2)$ & $21(26.9)$ & 0.009 \\
\hline Glatiramer acetate & $36(17.6)$ & $13(18.8)$ & $6(10.3)$ & $17(21.8)$ & 0.600 \\
\hline Other & $5(2.4)$ & $2(2.9)$ & $1(1.7)$ & $2(2.6)$ & 0.907 \\
\hline
\end{tabular}

MS multiple sclerosis, SD standard deviation, min minimum, max maximum, DMD disease-modifying drug, SC IFN 3 -1b subcutaneous interferon beta-1b, IM IFN $\beta$ - $1 a$ intramuscular interferon beta-1a

${ }^{\dagger}$ Percentages do not sum up to $100 \%$ due to multiple responses

${ }^{\ddagger}$ Percentages were compared between the groups: no mark indicates $P$ values for chi-square tests, and an asterisk $(*)$ indicates $P$ values for one-way ANOVA

experience with MS treatment. The most common affiliation was hospitals in general (38.5\%), although there was a significant difference in the distribution of affiliations among 3 groups, with hospitals in general being the most common in group $1(40.6 \%)$ and group $2(46.6 \%)$ while university hospitals being the most common in group $3(42.3 \%)(p=0.019)$. The percentages of respondents who have prescribed NTZ or GA, DMDs launched in 2014 or after, were low at 15.6 and $17.6 \%$, respectively, whereas those of respondents who have prescribed subcutaneous IFN $\beta-1 b$, intramuscular IFN $\beta-1 \mathrm{a}$ and FTY were high at 97.1, 87.8 and $83.4 \%$, respectively. The percentages of respondents who have prescribed FTY and NTZ were 
the highest in group 3 (94.9 and 26.9\%, respectively), with significant differences among 3 groups (FTY: $p<0.001$, NTZ: $p=0.009$ ).

\section{Diagnosis of relapsing remitting MS (RRMS) based on McDonald criteria}

To determine the acknowledgement of the 2010 revised McDonald diagnostic criteria, we used a question "Can dissemination in time and space be determined for the purpose of diagnosing relapsing remitting MS (RRMS) in the presence of 1 clinical attack with a single MRI scan?" (Table 2). To this question, $86.3 \%$ of the respondents answered "yes", indicating that the 2010 revised McDonald diagnostic criteria are used as the consensus criteria. The percentage of respondents answering "yes" also significantly increased with increasing number of patients under care (trend test $p=0.014$ ).

\section{Determination of clinical relapse and use of MRI scan}

The survey results on the determination of clinical relapse and use of MRI scan are summarized in Table 3. There was consensus in diagnosing clinical relapse based on "new/worsening symptoms lasting $\geq 24$ hours in the absence of comorbidities, such as acute infection" and "worsening neurological exam" (98.0\%). In contrast, "new/worsening symptoms lasting $\geq 24$ hours" was not a consensus criterion for diagnosing clinical relapse if either "no neurological exam was performed" or "no change in neurological exam" applied (47.8 and 51.7\%, respectively). We then asked the question "In a patient presenting with a clinical relapse based on your definition of a relapse, do you usually order an MRI scan?" To this question, all respondents answered "yes". In addition, $63.4 \%$ of respondents answered yes to the question "Does the appearance of new asymptomatic MRI activity constitute the equivalent of a clinical relapse?", although consensus was not achieved. No significant intergroup difference was observed in any of these questions.
Timing of starting DMD treatment and timing of MRI scan after start of DMD treatment

We presented case scenarios 1, 2 and 3 where untreated patients have different levels of disease activity (the lowest in case 1 and the highest in case 3) and investigated when physicians decide to start treatment in case scenarios 1 and 2 (Table 4). There was consensus in starting DMD treatment in both case scenarios (91.2 and 96.6\%, respectively). Performing follow-up MRI scans within 6 months after the start of DMD treatment in cases 1 and 3 also reached consensus (85.6 and 88.3\%, respectively).

\section{Relationship between the number of clinical relapses or new MRI lesions after start of DMD treatment and switching of DMDs}

The question "Assuming a patient is currently receiving treatment, what is the minimum number of clinical relapses over 6 months or 12 months that would prompt you to suggest a change in DMD?" was asked (Table 5). There was consensus in considering switching from one DMD to another after 1 to 2 clinical relapses either within 6 or 12 months after the start of treatment (96.5 and $77.1 \%$, respectively). There was no significant difference among groups in all cases. In the next question, we assumed 2 case scenarios, where a patient has been receiving the same treatment for 2 years, and no changes in MRI were observed on scans after 1 year of treatment, but activity was observed on a routine MRI performed after 2 years of treatment (case 1), or no changes in MRI were observed on scans at 1 and 2 years, but activity was observed on a routine MRI performed after 3 years of treatment (case 2), and asked "what is the lowest number of new T2 or gadolinium-enhanced ( $\mathrm{Gd}+$ ) lesions that would prompt you to suggest a change in DMD?" (Table 5). In terms of the number of new T2 lesions, the most frequent answer was " 2 " or " $3-4$ " in both cases (32.7 and $33.2 \%$ in case $1 ; 33.7$ and $31.2 \%$ in case 2 , respectively). In terms of the number of new $\mathrm{Gd}+$ lesions, the most frequent answer was " 1 " followed by " 2 " in both cases ( 47.3 and $34.6 \%$ in case $1 ; 46.3$ and $30.7 \%$ in case 2 , respectively). Thus,

Table 2 Diagnosis of RRMS based on the McDonald criteria

\begin{tabular}{|c|c|c|c|c|c|c|}
\hline \multirow[t]{2}{*}{ Question and answer } & \multirow{2}{*}{$\begin{array}{l}\text { Overall } \\
(\mathrm{n}=205)\end{array}$} & \multicolumn{3}{|c|}{ Sub-group by the number of MS patients under care } & \multicolumn{2}{|l|}{$P$ value } \\
\hline & & $\begin{array}{l}\text { Group 1: } \\
1-3 \text { patients }(n=69)\end{array}$ & $\begin{array}{l}\text { Group 2: } \\
\text { 4-9 patients }(n=58)\end{array}$ & $\begin{array}{l}\text { Group 3: } \\
\geq 10 \text { patients }(n=78)\end{array}$ & Group comparison $^{*}$ & Trend test $^{\dagger}$ \\
\hline \multicolumn{7}{|c|}{$\begin{array}{l}\text { Question: Can dissemination in time and space be determined for the purpose of diagnosing RRMS in the presence of } 1 \text { clinical attack with a single } \\
\text { MRI scan? }\end{array}$} \\
\hline Yes, n (\%) & $177(86.3)$ & $54(78.3)$ & $51(87.9)$ & $72(92.3)$ & $\begin{array}{l}0.152^{a} \\
0.015^{b} \\
0.391^{c}\end{array}$ & 0.014 \\
\hline
\end{tabular}

RRMS relapsing remitting multiple sclerosis, MS multiple sclerosis, MRI magnetic resonance imaging

"Percentages were compared in groups of two using the chi-square test, and the corresponding $P$ values are indicated for the following comparisons: a: Group 1 vs. Group 2, b: Group 1 vs. Group 3, c: Group 2 vs. Group 3

${ }^{+}$The trend across the three groups was tested using the Cochran-Armitage test 
Table 3 Criteria for a clinical relapse and application of MRI for judgement for a relapse

\begin{tabular}{|c|c|c|c|c|c|c|}
\hline \multirow[t]{2}{*}{ Questions and answers } & \multirow{2}{*}{$\begin{array}{l}\text { Overall } \\
(n=205)\end{array}$} & \multicolumn{3}{|c|}{ Sub-group by the number of MS patients under care } & \multicolumn{2}{|l|}{ P value } \\
\hline & & $\begin{array}{l}\text { Group 1: } \\
1-3 \text { patients }(n=69)\end{array}$ & $\begin{array}{l}\text { Group 2: } \\
\text { 4-9 patients }(n=58)\end{array}$ & $\begin{array}{l}\text { Group 3: } \\
\geq 10 \text { patients }(n=78)\end{array}$ & Group comparison ${ }^{*}$ & $\begin{array}{l}\text { Trend } \\
\text { test }^{\dagger}\end{array}$ \\
\hline \multicolumn{7}{|c|}{ Question 1: Do any of the following constitute a clinical relapse in your practice (in the absence of comorbidities, such as acute infection)? } \\
\hline $\begin{array}{l}\text { a. New/worsening symptoms lasting } \\
>24 \mathrm{~h} \text {, no neurological exam } \\
\text { performed, } \mathrm{n}(\%)\end{array}$ & $98(47.8)$ & $29(42.0)$ & $31(53.4)$ & $38(48.7)$ & $\begin{array}{l}0.199^{\mathrm{a}} \\
0.416^{\mathrm{b}} \\
0.585^{\mathrm{c}}\end{array}$ & 0.437 \\
\hline $\begin{array}{l}\text { b. New/worsening symptoms lasting } \\
>24 \mathrm{~h} \text {, no change in neurological } \\
\text { exam, } \mathrm{n}(\%)\end{array}$ & $106(51.7)$ & $29(42.0)$ & $34(58.6)$ & $43(55.1)$ & $\begin{array}{l}0.063^{\mathrm{a}} \\
0.113^{\mathrm{b}} \\
0.684^{\mathrm{c}}\end{array}$ & 0.122 \\
\hline $\begin{array}{l}\text { c. New/worsening symptoms lasting } \\
>24 \mathrm{~h} \text { and worsening neurological } \\
\text { exam, } \mathrm{n}(\%)\end{array}$ & $201(98.0)$ & $67(97.1)$ & $57(98.3)$ & $77(98.7)$ & $\begin{array}{l}0.664^{\mathrm{a}} \\
0.489^{\mathrm{b}} \\
0.832^{\mathrm{c}}\end{array}$ & 0.483 \\
\hline \multicolumn{7}{|c|}{ Question 2: In a patient presenting with a clinical relapse based on your definition of a relapse, do you usually order an MRI scan? } \\
\hline Yes, n (\%) & $205(100.0)$ & $69(100.0)$ & $58(100.0)$ & $78(100.0)$ & - & - \\
\hline \multicolumn{7}{|c|}{ Question 3: Does the appearance of new asymptomatic MRI activity constitute the equivalent of a clinical relapse? } \\
\hline Yes, n (\%) & $130(63.4)$ & $43(62.3)$ & $38(65.5)$ & $49(62.8)$ & $\begin{array}{l}0.709^{a} \\
0.950^{b} \\
0.746^{c}\end{array}$ & 0.960 \\
\hline
\end{tabular}

MRI magnetic resonance imaging, MS multiple sclerosis

*Percentages were compared between two groups using the chi-square test, and the corresponding $P$ values are indicated for the following comparisons: a: Group 1 vs. Group 2, b: Group 1 vs. Group 3, c: Group 2 vs. Group 3

${ }^{\dagger}$ The trend across the three groups was tested using the Cochran-Armitage test

there was consensus in considering change of DMDs after 1-2 new Gd + lesions were detected. No significant difference was observed among groups.

\section{Selection of DMDs at start of treatment}

The selection of DMDs at the start of treatment in cases 1 to 3 was asked as shown in Table 4 to investigate the relationship between disease activity and DMD selection (Fig. 1). In all cases, most of the respondents answered to choose IFN $\beta$ products or FTY (IFN $\beta$ : $70.0 \%$ in case 1 , 64.7\% in case 2 and 54.7\% in case 3, FTY: 25.1, 27.3 and 37.1\%). At the same time, increasing disease activity was associated with decreasing prescription of IFN $\beta$ and increasing prescription of FTY. This trend was especially evident in group 3 . The percentage of respondents choosing IFN $\beta$ products decreased from $77.5 \%$ in case 1 to $61.8 \%$ in case 2 and then to $48.7 \%$ in case 3 while that for FTY increased from 19.7 to $31.6 \%$ and then to $48.7 \%$. In groups 1 and 2, no substantial difference was observed in DMD selections according to disease activity. The percentages of respondents choosing FTY in case 3 were 30.4, 29.3 and $48.7 \%$ in groups 1,2 and 3, respectively, being the highest in group 3 . This indicates that respondents with greater treatment experience tend to take disease activity into consideration when choosing DMDs. As for DMDs launched in 2014 or after, the percentage of respondents choosing GA decreased with increasing disease activity from 2.7 to $2.0 \%$ and then to $1.0 \%$ while that for NTZ increased from 1.6 to $3.0 \%$ and then to $5.4 \%$ in cases negative for anti-JCV antibody.

\section{Switching of DMDs}

A question on switching of DMDs in cases of suboptimal response to current DMDs was asked. Respondents were allowed to select DMDs they have not used or those that have not been adopted at the affiliating institution. The results are summarized in Table 6. Non-FTY DMDs were most frequently switched to FTY, while FTY was most frequently switched to NTZ regardless of anti-JCV antibody status. The percentage of respondents switching from other DMDs to NTZ was higher in cases negative for anti-JCV antibody compared to when the anti-JCV antibody status was not taken into account (3.9\% vs. $7.8,6.3 \%$ vs. $10.2,52.2 \%$ vs. 56.6 , and $21.0 \%$ vs. $25.4 \%$, respectively).

\section{Discussion}

The results of the present survey study partially revealed the current practices of diagnosing and determining the treatment strategy for MS in Japan. In this section, we discuss the following four aspects:

\section{Acknowledgements of the 2010 revised McDonald diagnostic criteria}

There is consensus that RRMS can be diagnosed based on the 2010 revised McDonald criteria [7] and the percentage in favor of this notion significantly increased with increasing number of patients under care. A high accordance with the criteria was expected prior to this study because our original criteria for diagnosing MS as a designated intractable disease had been constructed based on the 2010 revised McDonald criteria [7]. Patients who are diagnosed 
Table 4 Timing for initiation of DMD treatment and follow-up MRI for the case scenarios

\begin{tabular}{|c|c|c|c|c|c|c|}
\hline \multirow{2}{*}{$\begin{array}{l}\text { Case scenario, questions } \\
\text { and answers }\end{array}$} & \multirow{2}{*}{$\begin{array}{l}\text { Overall } \\
(n=205)\end{array}$} & \multicolumn{3}{|c|}{ Sub-group by the number of MS patients under care } & \multicolumn{2}{|l|}{$P$ value } \\
\hline & & $\begin{array}{l}\text { Group 1: } \\
\text { 1-3 patients }(n=69)\end{array}$ & $\begin{array}{l}\text { Group 2: } \\
\text { 4-9 patients }(n=58)\end{array}$ & $\begin{array}{l}\text { Group 3: } \\
\geq 10 \text { patients }(n=78)\end{array}$ & parison ${ }^{*}+$ & Trend test ${ }^{\ddagger}$ \\
\hline
\end{tabular}

Case 1: A 25-year-old man with RRMS and 2 clinical relapses in the last 4 years is treatment naive and presents with a normal neurologic exam. A recent MRI reveals 5 non-enhancing T2 lesions in the brain.

Question 1: Would you initiate $\mathrm{DMD}^{\#}$ treatment?

Yes, n (\%) $187(91.2)-63(91.3)$

$53(91.4)$

$71(91.0)$

$0.988^{\mathrm{a}}$

$0.953^{\mathrm{b}}$

$0.943^{\mathrm{c}}$

Question 2: If you answered yes in Question 1, when would you perform the follow-up MRI?

$\begin{array}{llllll}\text { Follow-up timing, } \mathrm{n} / 187(\%)^{\S} & & & \\ \leq 3 \text { months } & 62(33.2) & 22(34.9) & 17(32.7) & 23(32.4) & 0.480^{\mathrm{a}} \\ >3-\leq 6 \text { months } & 98(52.4) & 31(49.2) & 25(48.1) & 42(59.2) & 0.331^{\mathrm{b}} \\ >6-\leq 12 \text { months } & 24(12.8) & 10(15.9) & 8(15.1) & 6(8.5) & 0.197^{\mathrm{c}} \\ >12 \text { months } & 2(1.1) & 0(0.0) & 2(3.8) & 0(0.0)\end{array}$

Case 2: Assume that you are presented with the Case 1 patient with RRMS who remains as treatment naïve and has had 2 clinical relapses in close proximity (last 6 months) that have left him with a residual disability. MRI reveals multiple, extensive, non-enhancing T2 lesions in the brain, brainstem, and spinal cord.

Question 3: Would you initiate DMD\# $^{\#}$ treatment?

Yes, n (\%) 198 (96.6) 65 (94.2)

$57(98.3)$

$76(97.4)$

$0.240^{\mathrm{a}}$

$0.323^{b}$

$0.742^{\mathrm{C}}$

0.294

Case 3: Assume that you are presented with the Case 1 patient with RRMS who remains as treatment naïve and has had 2 clinical relapses in close proximity (last 6 months) that have left him with residual disability. MRI shows multiple, extensive, non-enhancing T2 lesions in the brain, brainstem, and spinal cord; multiple T1 hypointense lesions; and brain atrophy.

Question 4: Following initiation of therapy, when would you perform a follow-up MRI?

Follow-up timing, n/205 (\%)

$\begin{array}{llllll}\leq 3 \text { months } & 95(46.3) & 36(52.2) & 24(41.4) & 35(44.9) & 0.200^{\mathrm{a}} \\ >3-\leq 6 \text { months } & 86(42.0) & 28(40.6) & 23(39.7) & 35(44.9) & 0.626^{\mathrm{b}} \\ >6-\leq 12 \text { months } & 23(11.2) & 5(7.2) & 10(17.2) & 8(10.3) & 0.411^{c} \\ >12 \text { months } & 1(0.5) & 0(0.0) & 1(1.7) & 0(0.0)\end{array}$

DMD disease-modifying drug, DMT disease-modifying therapy, MRI magnetic resonance imaging, MS multiple sclerosis, RRMS relapsing-remitting multiple sclerosis, SC IFN $\beta$ - 16 subcutaneous interferon beta- $1 \mathrm{~b}$, IM IFN $\beta$ - $1 a$ intramuscular interferon beta- $1 \mathrm{a}$, JCV John Cunningham virus

"Percentages were compared in groups of two using the chi-square test, and the corresponding $p$-values are indicated for the following comparisons: a: Group 1 vs. Group 2, b: Group 1 vs. Group 3, c: Group 2 vs. Group 3

${ }^{\dagger}$ The distributions of selected DMDs were compared among the three groups using the chi-square test

${ }^{\ddagger}$ The trend across the three groups was tested using the Cochran-Armitage test for a binominal response or Cochrane-Mantel-Haenszel test for a multiple response

\#In the actual question, the term DMT was used instead of DMD added supplementary explanation which means DMD

${ }^{5}$ Responses of only those who reported that they would initiate DMD for each case were calculated

with MS based on the original criteria and satisfy certain conditions are eligible for an application to publicly subsidized medical care. This high accordance with the 2010 revised McDonald diagnostic criteria could have been boosted by the health care system in Japan.

\section{Determination of relapse and use of MRI scan}

In the presence of new/worsening symptoms lasting $\geq 24$ h, only about $50 \%$ of respondents diagnosed clinical relapse if no neurological examination was performed or no worsening in neurological examination was noted, whereas $98 \%$ of respondents diagnosed relapse if worsening of neurological examination was noted, suggesting that worsening of neurological examination is a key criterion for diagnosing clinical relapse. Furthermore, $63 \%$ of respondents acknowledges that the appearance of new asymptomatic MRI activity represents clinical relapse. The fact that even with clinical evidence of relapse, all respondents performed MRI scan as a key criterion for diagnosing relapse suggests that MRI scan is considered an important modality for determining relapse, regardless of treatment experience.

\section{Timing of starting DMD treatment in untreated patients and selection of DMDs}

In the questions about the timing of starting DMD treatment, more than $90 \%$ of respondents in all groups answered that they would start treatment in case scenarios 
Table 5 Change criteria of DMD by the number of relapses and lesions by case scenarios

\begin{tabular}{|c|c|c|c|c|c|c|}
\hline \multirow{2}{*}{$\begin{array}{l}\text { Case scenario, questions } \\
\text { and answers }\end{array}$} & \multirow{2}{*}{$\begin{array}{l}\text { Overall } \\
(n=205)\end{array}$} & \multicolumn{3}{|c|}{ Sub-group by number of MS patients under care } & \multicolumn{2}{|l|}{$P$ value } \\
\hline & & $\begin{array}{l}\text { Group 1: } \\
1-3 \text { patients }(n=69)\end{array}$ & $\begin{array}{l}\text { Group 2: } \\
\text { 4-9 patients }(n=58)\end{array}$ & $\begin{array}{l}\text { Group 3: } \\
\geq 10 \text { patients }(n=78)\end{array}$ & Group comparison $^{*}$ & Trend test $^{\dagger}$ \\
\hline
\end{tabular}

Question 1: Assuming a patient is currently receiving treatment, what is the minimum number of clinical relapses over 6 months or 12 months that would prompt you to suggest a change in $\mathrm{DMD}^{\ddagger}$ ?

\begin{tabular}{|c|c|c|c|c|c|c|}
\hline \multicolumn{7}{|c|}{ Number of relapses over 6 months, $n(\%)$} \\
\hline 1 clinical relapse & $120(58.5)$ & $38(55.1)$ & 34 (58.6) & $48(61.5)$ & \multirow{4}{*}{$\begin{array}{l}0.799^{a} \\
0.288^{b} \\
0.684^{c}\end{array}$} & \multirow[t]{4}{*}{0.238} \\
\hline 2 clinical relapses & $78(38.0)$ & $27(39.1)$ & $22(37.9)$ & $29(37.2)$ & & \\
\hline 3 clinical relapses & $7(3.4)$ & $4(5.8)$ & $2(3.4)$ & $1(1.3)$ & & \\
\hline$\geq 4$ clinical relapses & $0(0.0)$ & $0(0.0)$ & $0(0.0)$ & $0(0.0)$ & & \\
\hline \multicolumn{7}{|c|}{ Number of relapses over 12 months, $\mathrm{n}(\%)$} \\
\hline 1 clinical relapse & $56(27.3)$ & $13(18.8)$ & $21(36.2)$ & $22(28.2)$ & \multirow{4}{*}{$\begin{array}{l}0.175^{a} \\
0.454^{b} \\
0.731^{c}\end{array}$} & \multirow[t]{4}{*}{0.308} \\
\hline 2 clinical relapses & 102 (49.8) & $39(56.5)$ & $25(43.1)$ & $38(48.7)$ & & \\
\hline 3 clinical relapses & $36(17.6)$ & $12(17.4)$ & $9(15.5)$ & $15(19.2)$ & & \\
\hline$\geq 4$ clinical relapses & $11(5.4)$ & $5(7.2)$ & $3(5.2)$ & $3(3.8)$ & & \\
\hline
\end{tabular}

Case 1: Assuming a patient with clinically stable RRMS has been receiving the same treatment for 2 years, and no changes in MRI were seen on scans after 1 year of therapy, but activity was seen on a routine MRI performed after 2 years of treatment.

Question 2: What is the lowest number of new T2 or Gd + lesions that would prompt you to suggest a change in $\mathrm{DMD}^{\ddagger}$ ?

Number of $\mathrm{T} 2$ lesions, $\mathrm{n}(\%)$

$\begin{array}{llllll}1 \text { T2 lesion } & 30(14.6) & 7(11.9) & 14(28.0) & 9(13.2) & 0.006^{\mathrm{a}} \\ \text { 2 T2 lesions } & 67(32.7) & 27(45.8) & 10(20.0) & 30(44.1) & 0.985^{\mathrm{b}} \\ \text { 3-4 T2 lesions } & 68(33.2) & 23(39.0) & 19(38.0) & 26(38.2) & 0.010^{c} \\ \geq 5 \text { T2 lesions } & 12(5.9) & 2(3.4) & 7(14.0) & 3(4.4)\end{array}$

Number of Gd + lesion, $\mathrm{n}(\%)$

$\begin{array}{llllll}1 \mathrm{Gd}+\text { lesion } & 97(47.3) & 29(45.3) & 30(58.8) & 38(52.8) & 0.318^{\mathrm{a}} \\ 2 \mathrm{Gd}+\text { lesions } & 71(34.6) & 27(42.2) & 15(29.4) & 29(40.3) & 0.471^{\mathrm{b}} \\ \geq 3 \mathrm{Gd}+\text { lesions } & 19(9.3) & 8(12.5) & 6(11.8) & 5(6.9) & 0.376^{\mathrm{c}}\end{array}$

$$
\begin{aligned}
& 0.318^{a} \\
& 0.471^{b} \\
& 0.376^{c}
\end{aligned}
$$$$
6(11.8) \quad 5(6.9)
$$

Case 2: Assuming a patient with clinically stable RRMS has been receiving the same treatment for 2 years, and no changes in MRI were seen on scans at 1 and 2 years.

Question 3: What is the lowest number of new $\mathrm{T} 2$ or $\mathrm{Gd}+$ lesions on a subsequent routine MRI that would prompt you to suggest a change in $\mathrm{DMD}^{\ddagger}$ ?

Number of $\mathrm{T} 2$ lesions, $\mathrm{n}(\%)$

$\begin{array}{llllll}1 \text { T2 lesion } & 23(11.2) & 5(8.6) & 11(22.4) & 7(10.0) & 0.118^{\mathrm{a}} \\ \text { 2 T2 lesions } & 69(33.7) & 25(43.1) & 14(28.6) & 30(42.9) & 0.841^{\mathrm{b}} \\ \text { 3-4 T2 lesions } & 64(31.2) & 23(39.7) & 17(34.7) & 24(34.3) & 0.205^{\mathrm{c}} \\ \geq \text { 5 T2 lesions } & 21(10.2) & 5(8.6) & 7(14.3) & 9(12.9)\end{array}$

Number of Gd + lesion, $\mathrm{n}(\%)$

$\begin{array}{llllll}1 \mathrm{Gd}+\text { lesion } & 95(46.3) & 27(42.9) & 29(56.9) & 39(54.2) & 0.224^{\mathrm{a}} \\ 2 \mathrm{Gd}+\text { lesions } & 63(30.7) & 22(34.9) & 16(31.4) & 25(34.7) & 0.180^{\mathrm{b}} \\ \geq 3 \mathrm{Gd}+\text { lesions } & 28(13.7) & 14(22.2) & 6(11.8) & 8(11.1) & 0.927^{\mathrm{c}}\end{array}$

$D M D$ disease-modifying drug, DMT disease-modifying therapy, MS multiple sclerosis, RRMS relapsing-remitting multiple sclerosis, $M R I$ magnetic resonance imaging, $G d+$ gadolinium enhancement

*Percentages were compared between two groups using the chi-square test, and the corresponding P values are indicated for the following comparisons: a: Group 1 vs. Group 2, b: Group 1 vs. Group 3, c: Group 2 vs. Group 3

${ }^{\dagger}$ A trend across three groups was tested using the Cochrane-Mantel-Haenszel test

${ }^{\ddagger}$ In the actual question, the term DMT was used instead of DMD added supplementary explanation which means DMD

1 and 2, indicating consensus about the need for early treatment, regardless of treatment experience (Table 5). For treatment of untreated patients, most of the respondents chose IFN $\beta$ products or FTY, although increasing disease activity was associated with decreasing prescription of IFN $\beta$ products and increasing prescription 


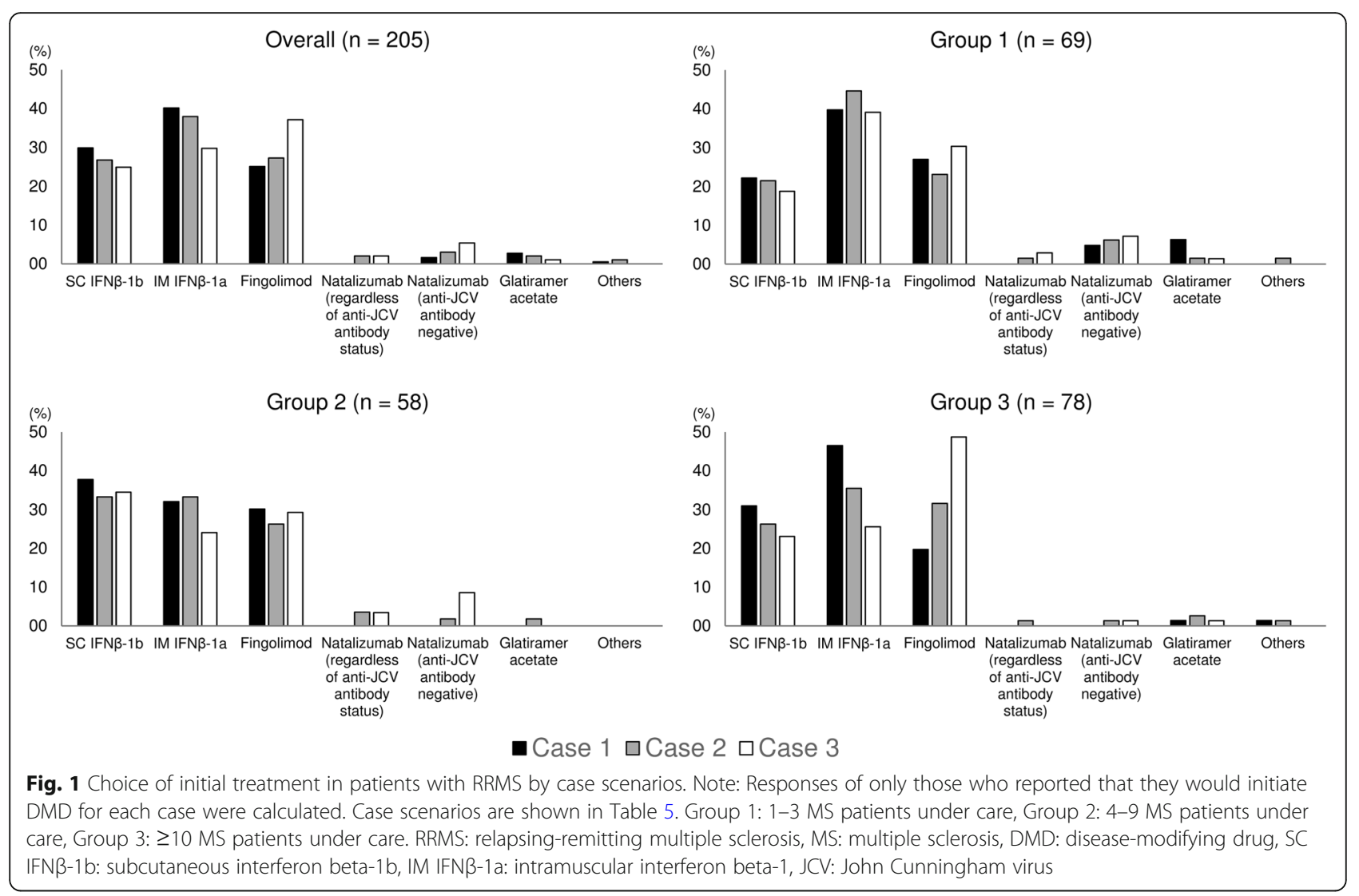

of FTY. This trend was especially evident in group 3, while in groups 1 and 2, the same DMDs tended to be selected independent of disease activity, suggesting that physicians with greater treatment experience tend to choose DMDs according to disease activity. A previous study conducted in the U.S. in 2011 showed that increasing disease activity was associated with increased variability of prescribed DMDs; in particular, the prescription rate of NTZ, a relatively potent DMD, increased substantially (case 2: 32\%, case 3: 39\%) while that of FTY increased minimally (case 2: $1 \%$, case $3: 4 \%$ ) [11]. In follow-up study conducted in 2014 , if the anti-JCV antibody was negative, $89 \%$ of respondents answered that NTZ was selected for Case 3 (36.6\% in the case of anti-JCV antibody positive) [12]. The reasons of this discrepancy between Japan and the U.S. were considered as follows; differential demographics of respondents, where U.S. respondents were board-certified specialists in MS treatment who were treating up to 900 MS patients on average, compared with an approximate average of 9 patients treated by the respondents of our survey, the wide acceptance to use drugs with higher efficacy for patients with short MS history among MS specialists in the U.S. [11, 12], earlier launch of NTZ than FTY in the U.S., and higher prevalence of anti-JCV antibody in the Japanese population compared to the Western population [14-19].

\section{Switch of DMDs}

There was consensus that 1-2 clinical relapses over 6 months of treatment with a DMD would lead to switching from one DMD to another (96.6\%). However, no consensus was achieved regarding the minimum number of clinical relapses over 1 year that would lead to treatment switch, suggesting a lack of sufficient information to determine the timing of treatment switch. The strategy for switching treatment due to suboptimal response to the current treatment was not affected by the anti-JCV antibody status, with the most common pattern being from a non-FTY DMD to FTY and from FTY to NTZ. A U.S. study conducted in 2014 showed with switching to oral drugs being the most common either from injectables (GA, IFN $\beta ; 83.8 \%$ ), oral drugs (DMF, FTY, teriflunomide; 75.5\%) or IV infusion (NTZ; $89.9 \%$ ) in cases positive for anti-JCV antibody [12]. In contrast, in cases negative for anti-JCV antibody, the most common patterns were switching to NTZ from injectables $(46.0 \%)$ or oral drugs $(69.2 \%)$ and switching to oral drugs from NTZ (83.2\%) [12]. From these results of Japan and the U.S. study, it is considered that Japanese neurologists and U.S. specialists were practically choosing DMDs according to disease activity taking into account the risk of progressive multifocal leukoencephalopathy at the time of switching in the case of anti-JCV 


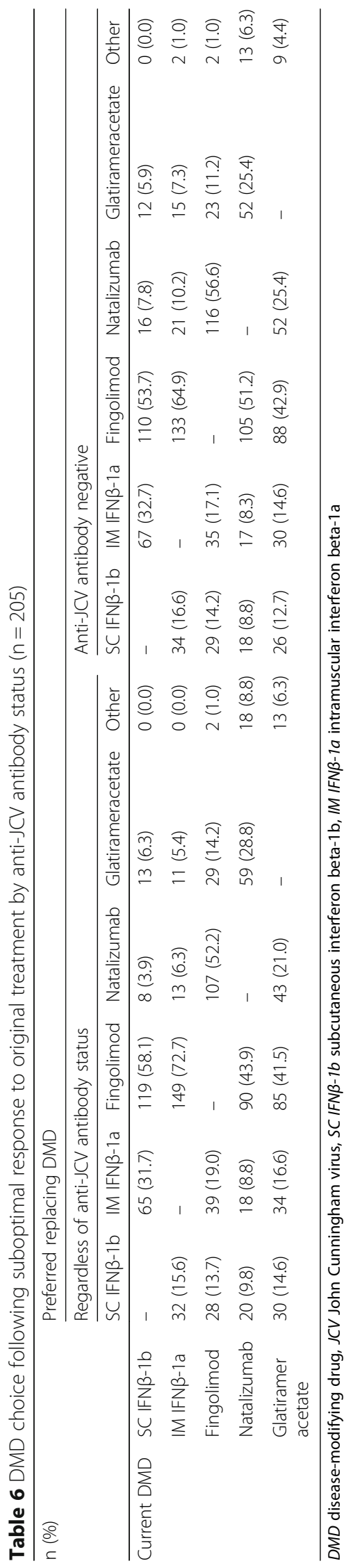


antibody positive. However, in the case of anti-JCV antibody negative, it became clear that in the United States, drugs that strongly suppress disease activity are preferred to prescribe.

\section{Limitations of the study}

There is a sampling bias in this study. First, the number of neurologists in Japan in 2016 when the present survey conducted was 4657 [20], but the present survey was conducted using a panel of 3743 neurologists. Second, only 376 neurologists from the panel responded. Third, responders might be in a biased population consisting mainly of those interested in collecting medical information from the Internet. Lastly, the population may also be biased in that the number of MS patients under care by the respondents ranged from 1 to 50 and there was no specialist treating a larger number of patients. In Japan, however, MS specialists providing more than 50 patients with treatment is extremely limited, unlike in North America, because of the significantly lower prevalence of MS in Japan [2,3]. Members $(n=36)$ of the Japanese Society for Neuroimmunology could be regarded as MS specialists in Japan, because the society is focusing on MS and several intractable neurologic diseases. Therefore, we think most of the responders were typical MS neurologists in Japan in terms of the number of MS patients under care. The results should therefore be interpreted with caution, but at least, this study partially revealed the current diagnosis and therapeutic decision-making patterns for multiple sclerosis treatment in Japan and should provide some insights considering the scarcity of reports so far.

\section{Conclusion}

This survey study is meaningful in that it collected opinions from 205 neurologists engaged in MS treatment throughout Japan. This study revealed that Japanese neurologists consider both the 2010 revised McDonald diagnostic criteria and MRI scan indispensable for MS diagnosis and determination of relapse, regardless of treatment experience. Conversely, physicians with greater treatment experience tend to choose DMDs according to disease activity. Because the population includes neurologists with various levels of experience, the results are likely to reflect the current clinical practice for MS patients in Japan.

This study will contribute to improved clinical practice for MS patients in Japan by revealing some aspects of the current practice.

\section{Abbreviations}

ANOVA: analysis of variance; DMD: disease-modifying drug; DMF: dimethyl fumarate; FTY: fingolimod; GA: glatiramer acetate; IFN $\beta$ : interferon beta; MS: multiple sclerosis; NTZ: natalizumab; RRMS: relapsing remitting multiple sclerosis

\section{Acknowledgments}

We would like to express our gratitude to all neurologists participating in this survey. We would like to thank Ms. Mika Kawaguchi and Mr. Norimasa Kikuchi of Clinical Study Support, Inc. (Nagoya, Japan) for preparing the draft manuscript, editing the manuscript and performing part of the analysis as directed by the authors. We would also like to thank Mr. Takamine Mochida of Kantar Japan (Tokyo, Japan) for their assistance in conducting the survey and other analyses.

\section{Funding}

The funds for the survey, analysis and manuscript writing were provided by Biogen Japan Ltd.

\section{Availability of data and materials}

The data that support the findings of this study are available from the corresponding author upon reasonable request.

\section{Authors' contributions}

$\mathrm{KH}$ and $\mathrm{MH}$ conceptualized and designed the study. $\mathrm{KH}, \mathrm{MH}$, and $\mathrm{HO}$ interpreted results of data analysis. $\mathrm{KH}$ drafted the manuscript, and $\mathrm{MH}$ and $\mathrm{HO}$ revised it critically for important intellectual content. All authors read and approved the final manuscript.

\section{Ethics approval and consent to participate}

Ethical approval was not obtained for this survey; however, ethical consideration was given to the participants. De-identified data were provided by M3, Inc. for the analysis, so that no individual responses were known to the authors. Consent to participate in the survey was obtained from all respondents.

\section{Consent for publication}

Consent to publication of survey results was obtained from all respondents.

\section{Competing interests}

Katsutoshi Hiramatsu is an employee of Biogen Japan Ltd. and receives salaries from the company and possess the company's stocks. Masakazu Hase was an employee of Biogen Japan Ltd., and received salaries from the company and possessed the company's stocks at the time of this study conducted. Hirofumi Ochi has no conflict of interest with any company, organization or group to be disclosed in relation to this study.

\section{Publisher's Note}

Springer Nature remains neutral with regard to jurisdictional claims in published maps and institutional affiliations.

\section{Author details}

${ }^{1}$ Biogen Japan Ltd., Nihonbashi 1-chome Mistui Building 14F, 4-1, Nihonbashi 1-chome, Chuo-ku, Tokyo 103-0027, Japan. ${ }^{2}$ Department of Geriatric Medicine and Neurology, Ehime University Graduate School of Medicine, 10-13 Dogo-Himata, Matsuyama, Ehime 790-8577, Japan.

Received: 6 September 2017 Accepted: 31 May 2018 Published online: 15 June 2018

\section{References}

1. Lublin FD, Reingold SC, Cohen JA, et al. Defining the clinical course of multiple sclerosis: the 2013 revisions. Neurology. 2014;83:278-86.

2. Houzen H, Niino M, Hirotani M, Fukazawa T, Kikuchi S, Tanaka K, Sasaki H. Increased prevalence, incidence, and female predominance of multiple sclerosis in northern Japan. J Neurol Sci. 2012;323(1-2):117-22.

3. Osoegawa M, Kira J, Fukazawa T, Fujihara K, Kikuchi S, Matsui M, Kohriyama T, Sobue G, Yamamura T, Itoyama Y, et al. Temporal changes and geographical differences in multiple sclerosis phenotypes in Japanese: nationwide survey results over 30 years. Mult Scler. 2009;15(2):159-73.

4. Ochi $\mathrm{H}$. Emerging new disease-modifying drugs for multiple sclerosis. Saishin-Igaku, vol. 71; 2016. p. 1149-58. [in Japanese]

5. McDonald WI, Compston A, Edan G, Goodkin D, Hartung HP, Lublin FD, et al. Recommended diagnostic criteria for multiple sclerosis: guidelines from the international panel on the diagnosis of multiple sclerosis. Ann Neurol. 2001;50:121-7. 
6. Polman CH, Reingold SC, Edan G, Filippi M, Hartung HP, Kappos L, et al. Diagnostic criteria for multiple sclerosis: 2005 revisions to the "McDonald criteria". Ann Neurol. 2005;58:840-6.

7. Polman CH, Reingold SC, Banwell B, Clanet M, Cohen JA, Filippi M, et al. Diagnostic criteria for multiple sclerosis: 2010 revisions to the McDonald criteria. Ann Neurol. 2011;69:292-302.

8. Filippi M, Rocca MA, Ciccarelli O, De Stefano N, Evangelou N, Kappos L, et al. MRI criteria for the diagnosis of multiple sclerosis: MAGNIMS consensus guidelines. Lancet Neurol. 2016;15:292-303.

9. Treatment guidelines for multiple sclerosis development committee Treatment guidelines for multiple sclerosis 2010. Tokyo: Igaku-Shoin; 2010 [in Japanese].

10. Japan Intractable Diseases Information Center. 13 Multiple sclerosis/optic neuromyelitis. In: Explanation, diagnosis criteria, and clinical personal Q8 498 records. Ministry of Health, Labour and Welfare in Japan. Year not stated. http://www.mhlw.go.jp/file/06-Seisakujouhou-10900000-Kenkoukyoku/ 0000089938.pdf [in Japanese]. Accessed 24 Jan 2017.

11. Tornatore C, Phillips JT, Khan O, Miller AE, Barnes CJ. Practice patterns of US neurologists in patients with CIS, RRMS, or RIS: a consensus study. Neurol Clin Pract. 2012;2:48-57.

12. Tornatore C, Phillips JT, Khan O, Miller AE, Hughes M. Consensus opinion of US neurologists on practice patterns in RIS, CIS, and RRMS. Neurol Clin Pract. 2016;6:329-38

13. Agresti A. An introduction to categorical data analysis. 2nd ed. New York: Wiley; 2007.

14. Taguchi F, Kajioka J, Miyamura T. Prevalence rate and age of acquisition of antibodies against JC virus and BK virus in human sera. Microbiol Immunol. 1982;26:1057-64

15. Tanaka M, Kinoshita M, Tanaka K. Anti-John Cunningham virus index in Japanese patients with multiple sclerosis and neuromyelitis optica-related disorder. J Clin Exp Immunol. 2015;6:309-11.

16. Bozic C, Richman S, Plavina T, Natarajan A, Scanlon JV, Subramanyam M, et al. Anti-John Cunnigham virus antibody prevalence in multiple sclerosis patients: baseline results of STRATIFY-1. Ann Neurol. 2011;70:742-50.

17. Bhan V, Lapierre Y, Freedman MS, Duquette P, Selchen D, Migounov V, et al. Anti-JC virus antibody prevalence in Canadian MS patients. Can J Neurol Sci. 2014:41:748-52

18. Trampe AK, Hemmeimann C, Stroet A, Haghikia A, Hellwig K, Wiendl H, et al. Anti-JC virus antibodies in a large German natalizumab-treated multiple sclerosis cohort. Neurology. 2012;78:1736-42.

19. Outteryck O, Ongagna JC, Duhamel A, Zéphir H, Collongues N, Lacour A, et al. Anti-JCV antibody prevalence in a French cohort of MS patients under natalizumab therapy. J Neurol. 2012;259:2293-8.

20. Ministry of Health, Labour and Welfare of Japan. The overall survey summary of physicians, dentists, and pharmacists in 2014, Ministry of Health, Labour and Welfare in Japan. In: Survey summary of physicians, dentists, and pharmacists in 2014. http://www.mhlw.go.jp/toukei/saikin/hw/ ishi/14/dl/gaikyo.pdf. [in Japanese] Accessed 12 April 2018.

\section{Ready to submit your research? Choose BMC and benefit from:}

- fast, convenient online submission

- thorough peer review by experienced researchers in your field

- rapid publication on acceptance

- support for research data, including large and complex data types

- gold Open Access which fosters wider collaboration and increased citations - maximum visibility for your research: over $100 \mathrm{M}$ website views per year

At BMC, research is always in progress.

Learn more biomedcentral.com/submissions 